\title{
Predictors of permanent disability among adults with spinal dysraphism
}

\author{
Matthew C. Davis, MD, ${ }^{1}$ Betsy D. Hopson, MSHA, ${ }^{2}$ Jeffrey P. Blount, MD, ${ }^{1}$ Rachel Carroll, MPH, ${ }^{3}$ \\ Tracey S. Wilson, MD, ${ }^{3}$ Danielle K. Powell, MD, MSPH, ${ }^{4}$ Amie B. Jackson McLain, MD, ${ }^{4}$ and \\ Brandon G. Rocque, MD, MS ${ }^{1}$
}

Departments of ${ }^{1}$ Neurosurgery, ${ }^{3}$ Urology, and ${ }^{4}$ Physical Medicine and Rehabilitation, University of Alabama at Birmingham; and ${ }^{2}$ Spina Bifida Program, Children's of Alabama, University of Alabama at Birmingham, Alabama

OBJECTIVE Predictors of permanent disability among individuals with spinal dysraphism are not well established. In this study, the authors examined potential risk factors for self-reported permanent disability among adults with spinal dysraphism.

METHODS A total of 188 consecutive individuals undergoing follow-up in an adult spinal dysraphism clinic completed a standardized National Spina Bifida Patient Registry survey. Chi-square tests and logistic regression were used to assess bivariate relationships, while multivariate logistic regression was used to identify factors independently associated with self-identification as "permanently disabled."

RESULTS A total of 106 (56.4\%) adults with spina bifida identified themselves as permanently disabled. On multivariate analysis, relative to completion of primary and/or secondary school, completion of technical school (OR 0.01, $95 \% \mathrm{Cl} 0-0.40 ; p=0.021)$, some college (OR 0.22, 95\% Cl 0.08-0.53; $p<0.001)$, college degree (OR $0.06,95 \% \mathrm{Cl}$ $0.003-0.66 ; p=0.019$ ), and holding an advanced degree (OR $0.12,95 \% \mathrm{Cl} 0.03-0.45 ; p=0.002$ ) were negatively associated with permanent disability. Relative to open myelomeningocele, diagnosis of closed spinal dysraphism was also negatively associated with permanent disability (OR $0.20,95 \% \mathrm{Cl} 0.04-0.90 ; p=0.036)$. Additionally, relative to no stool incontinence, stool incontinence occurring at least daily (OR 6.41,95\% $\mathrm{Cl} 1.56-32.90 ; p=0.009)$ or more than weekly (OR 3.43, 95\% CI 1.10-11.89; $p=0.033$ ) were both positively associated with permanent disability. There was a suggestion of a dose-response relationship with respect to the influence of educational achievement and frequency of stool incontinence on the likelihood of permanent disability.

CONCLUSIONS The authors' findings suggest that level of education and degree of stool incontinence are the strongest predictors of permanent disability among adults with spinal dysraphism. These findings will be the basis of efforts to improve community engagement and to improve readiness for transition to adult care in a multidisciplinary pediatric spina bifida clinic.

https://thejns.org/doi/abs/10.3171/2017.1.SPINE161044

KEY WORDS spinal dysraphism; employment; outcome assessment; adult; congenital

$\mathrm{S}$ PINAL dysraphism is the most common congenital abnormality of the spinal cord and the most complex congenital condition with high rates of survival into adulthood. ${ }^{6}$ While $75 \%$ of these individuals can expect to reach adulthood, ${ }^{6,10}$ there is great variability in the range and degree of disability, ${ }^{21}$ and multiple medical and psychosocial limitations pose challenges to full community engagement.
Results of studies on the impact of medical factors on quality of life and employment status among adults with spina bifida are conflicting., $, 8,10,31$ Current data are frequently extrapolated from studies that also include patients with cerebral palsy. ${ }^{3,36}$

In this retrospective cohort study, we compared adults with spinal dysraphism who identified themselves as permanently disabled with those who were employed, those

ABBREVIATIONS BMI = body mass index; HRQOL = health-related quality of life; NSBPR = National Spina Bifida Patient Registry; ROC = receiver operating characteristic . SUBMITTED August 29, 2016. ACCEPTED January 5, 2017.

INCLUDE WHEN CITING Published online May 26, 2017; DOI: 10.3171/2017.1.SPINE161044. 
seeking work, current students, volunteer workers, or homemakers with respect to their continence status for both bladder and bowel, education status, race, functional level of lesion, and medical comorbidities. We hypothesize that both medical and psychosocial factors interact to influence employment status in adults with spina bifida. The purpose of this study is to better appreciate the relative importance of these factors on employment status in this population.

\section{Methods}

\section{Patient Selection and Description of Transitional Spinal Dysraphism Program}

All individuals treated at the University of Alabama at Birmingham Multidisciplinary Transitional Spina Bifida Clinic between October 2010 and March 2016 were retrospectively identified in April 2016 from the computerized medical record. The Transitional Spina Bifida Clinic is a multidisciplinary clinic that includes providers in the fields of neurosurgery, urology, physical medicine and rehabilitation, social work, physical therapy, and occupational therapy. Adults attending this clinic carry a diagnosis of spinal dysraphism, including myelomeningocele, meningocele, split cord malformation, lipomyelomeningocele, dermal sinus tract, and "other." Data included in this study were collected for all adults with spina bifida as part of data collection for the National Spina Bifida Patient Registry (NSBPR, http://www.cdc.gov/ncbddd/spinabifida/ nsbprregistry.html) and during routine standard of care. Patients were asked to complete a standardized questionnaire at each clinic visit that included the variables under study. The sample size was determined by the number of patient for whom complete data points were available.

\section{Data Collection}

At each visit to the Multidisciplinary Transitional Spina Bifida Clinic, the clinic coordinator conducts an interview. All NSBPR variables are recorded at that time and entered into the NSBPR electronic medical record.

For each patient, the following data points were queried from the NSBPR electronic medical record: age, sex, body mass index (BMI, stratified as $<30$, between 30 and 40, and $>40$ ), primary diagnosis (open myelomeningocele, lipomyelomeningocele, diastematomyelia, or other), race (white, black, or other), ethnicity (Hispanic or Latino vs not Hispanic or Latino), education level (primary/secondary, technical school, some college, college degree, or advanced degree), insurance status (commercial insurance, Medicaid, Medicare, or "other"), indication of whether the patient transitioned to the adult spina bifida clinic from Children's of Alabama pediatric spina bifida clinic or other hospital (yes vs no), current bowel management program (yes vs no), current bladder management program (yes vs no), frequency of stool incontinence (at least daily, less than daily but more than weekly, less than weekly but more than monthly, less than monthly, never, or unable to assess), frequency of urinary incontinence (at least daily, less than daily but more than weekly, less than weekly but more than monthly, less than monthly, never, or unable to assess), ambulation status (ambulates in the com- munity, ambulates only within the home, ambulates only during organized therapy, or nonambulatory), functional level of the lesion (thoracic [no motor function in lower extremities], high lumbar [hip extension present], midlumbar [knee extension present], low lumbar [foot dorsiflexion present], or sacral [foot plantar flexion present]), presence of a ventricular shunt (yes vs no), and number of ventricular shunt revisions.

As part of the NSBPR questionnaire, patients were asked first whether they were currently employed. If yes, they specified full-time or part-time employment. If no, they selected one of the following reasons why they were not currently employed: seeking work, occasional worker, volunteer, child, student, retired, homemaker, or permanently disabled. Therefore, the question as it is asked ascertains the patient's perception of himself or herself as permanently disabled. The primary outcome of interest was permanent disability. The aforementioned employment data were therefore classified dichotomously as either permanently disabled or not permanently disabled. Of 188 patients, 156 had BMI data available, and 180 patients had insurance data available. Otherwise, there were no missing data points.

\section{Statistical Analysis}

First, descriptive statistics were used to analyze univariate relationships between permanent disability and other variables. Logistic regression analysis for comparison of continuous variables and chi-square determination for comparison of proportions were applied to find significant associations between covariates and permanent disability. To test for independent association between permanent disability and the predictor variables, a multivariate logistic regression model was constructed, including those variables with a p value $<0.2$ on bivariate analysis. Insurance status was not included in the multivariate model as it represents a strong mediating variable. A receiver operating characteristic (ROC) curve was fit for permanent disability as a function of those variables that remained significantly associated with permanent disability on multivariate analysis.

Associations with $\mathrm{p}<0.05$ were regarded as significant. JMP 12 (SAS Institute) was used for all statistical analyses. This study was approved by the institutional review board of the University of Alabama at Birmingham. The paper was prepared using the STROBE (Strengthening the Reporting of Observational Studies in Epidemiology) checklist for cohort studies.

\section{Results \\ Study Population}

A total of 188 adults with spina bifida were included. Patient age ranged from 19.1 to 74.6 years (median 28.5 years), and 119 (63.3\%) were female (Table 1). Diagnoses included open myelomeningocele (163 patients, $86.7 \%$ of total); lipomyelomeningocele (17 patients, $9.0 \%$ ); diastematomyelia (5 patients, $2.7 \%$ ); and 1 each with meningocele, myelocystocele, and fibrolipoma of the filum terminale (0.5\% each). Of the 188 patients, 109 (58.0\%) had completed primary and/or secondary school, $2(1 \%)$ had completed 
TABLE 1. Demographics, functional status of cohorts, and association with permanent disability

\begin{tabular}{|c|c|c|c|c|}
\hline Variable & All Patients $(n=188)$ & Employed $(n=82)^{*}$ & Permanent Disability $(n=106)$ & $\mathrm{p}$ Value $†$ \\
\hline Mean age in yrs & 31.4 (range 19.1-74.6) & 31.9 (SD 12.2) & 31.1 (SD 7.76) & 0.538 \\
\hline Sex & & & & 0.561 \\
\hline Female & $119(63.3)$ & $50(42.0)$ & $69(58.0)$ & \\
\hline Male & $69(36.7)$ & $32(46.4)$ & $37(53.6)$ & \\
\hline Primary diagnosis & & & & $<0.001$ \\
\hline Open myelomeningocele & $163(86.7)$ & $61(37.4)$ & $102(62.6)$ & \\
\hline Lipomyelomeningocele & $17(9.0)$ & $14(82.4)$ & $3(17.7)$ & \\
\hline Diastematomyelia & $5(2.7)$ & $5(100)$ & $0(0)$ & \\
\hline Other & $3(1.6)$ & $2(66.7)$ & $1(33.3)$ & \\
\hline Transition from Children's of Alabama & & & & 0.754 \\
\hline No & $117(62.2)$ & $50(42.7)$ & $67(57.3)$ & \\
\hline Yes & $71(37.8)$ & $32(45.1)$ & $39(54.9)$ & \\
\hline Race & & & & 0.199 \\
\hline White & $155(82.5)$ & $72(46.5)$ & $83(53.5)$ & \\
\hline Black & $31(16.5)$ & $9(29.0)$ & $22(71.0)$ & \\
\hline Other & $2(1.0)$ & $1(50.0)$ & $1(50.0)$ & \\
\hline Ethnicity & & & & 0.418 \\
\hline Not Hispanic or Latino & $185(98.4)$ & $80(43.2)$ & $105(56.8)$ & \\
\hline Hispanic or Latino & $3(1.6)$ & $2(66.7)$ & $1(33.3)$ & \\
\hline BMlf & & & & 0.596 \\
\hline$<30$ & $94(60.3)$ & $41(43.6)$ & $53(56.4)$ & \\
\hline $30-40$ & $40(25.6)$ & $17(42.5)$ & $23(57.5)$ & \\
\hline$>40$ & $22(14.1)$ & $7(31.8)$ & $15(68.2)$ & \\
\hline Education level & & & & $<0.001$ \\
\hline Primary/secondary & $109(58.0)$ & $28(25.7)$ & $81(74.3)$ & \\
\hline Technical school & $2(1)$ & $1(50)$ & $1(50)$ & \\
\hline Some college & $50(26.6)$ & $33(66.0)$ & $17(34.0)$ & \\
\hline College degree & $20(10.6)$ & $14(70.0)$ & $6(30.0)$ & \\
\hline Advanced degree & $7(3.7)$ & $6(85.7)$ & $1(14.3)$ & \\
\hline Insurance status§ & & & & $<0.001$ \\
\hline Commercial insurance & $83(46.1)$ & $51(61.5)$ & $32(38.5)$ & \\
\hline Medicaid & $60(33.3)$ & $13(21.7)$ & $47(78.3)$ & \\
\hline Medicare & $31(17.2)$ & $13(41.9)$ & $18(58.1)$ & \\
\hline Other & $6(3.3)$ & $2(33.3)$ & $4(66.7)$ & \\
\hline Active bowel management program & & & & 0.365 \\
\hline No & $143(76.1)$ & $65(45.5)$ & $78(54.5)$ & \\
\hline Yes & $45(23.9)$ & $17(37.8)$ & $28(62.2)$ & \\
\hline Active bladder management program (self-catheterization) & & & & 0.749 \\
\hline No & $55(29.3)$ & $23(41.8)$ & $32(58.2)$ & \\
\hline Yes & $133(70.3)$ & $59(44.4)$ & $74(55.6)$ & \\
\hline Stool incontinence frequency & & & & $<0.001$ \\
\hline At least daily & $25(13.3)$ & $4(16.0)$ & $21(84.0)$ & \\
\hline Less than daily, more than weekly & $30(15.9)$ & $8(26.7)$ & $22(73.3)$ & \\
\hline Less than weekly, more than monthly & $15(8.0)$ & $6(40.0)$ & $9(60.0)$ & \\
\hline Less than monthly & $8(4.2)$ & $3(37.5)$ & $5(62.5)$ & \\
\hline Never & $80(42.6)$ & $47(58.8)$ & $33(41.2)$ & \\
\hline Cannot assess & $30(15.9)$ & $14(46.7)$ & $16(53.3)$ & \\
\hline Urine incontinence frequency & & & & 0.037 \\
\hline At least daily & $48(25.5)$ & $15(31.3)$ & $33(68.8)$ & \\
\hline Less than daily, more than weekly & $11(5.9)$ & $4(36.4)$ & $7(63.6)$ & \\
\hline Less than weekly, more than monthly & $13(6.9)$ & $5(38.5)$ & $8(61.5)$ & \\
\hline Less than monthly & $4(2.1)$ & $0(0)$ & $4(100)$ & \\
\hline Never & $83(44.1)$ & $45(54.2)$ & $38(45.8)$ & \\
\hline Cannot assess & $29(15.4)$ & $13(44.8)$ & $16(55.2)$ & \\
\hline
\end{tabular}


» CONTINUED FROM PAGE 171

TABLE 1. Demographics, functional status of cohorts, and association with permanent disability

\begin{tabular}{|c|c|c|c|c|}
\hline Variable & All Patients $(n=188)$ & Employed $(n=82)^{*}$ & Permanent Disability $(n=106)$ & $\mathrm{p}$ Value $\dagger$ \\
\hline Functional lesion level & & & & 0.206 \\
\hline Thoracic (flaccid lower extremities) & $84(44.7)$ & $29(34.5)$ & $55(65.5)$ & \\
\hline High lumbar (hip flexion present) & $18(9.6)$ & $9(50.0)$ & $9(50.0)$ & \\
\hline Midlumbar (knee extension present) & $38(20.2)$ & $20(52.6)$ & $18(47.4)$ & \\
\hline Low lumbar (foot dorsiflexion present) & $16(8.5)$ & $8(50.0)$ & $8(50.0)$ & \\
\hline Sacral (foot plantar flexion present) & $32(17.0)$ & $15(46.9)$ & $17(53.1)$ & \\
\hline Independent ambulation & & & & 0.021 \\
\hline Community ambulation & $54(28.7)$ & $33(61.1)$ & $21(38.9)$ & \\
\hline Household ambulation & $14(7.4)$ & $6(42.9)$ & $8(57.1)$ & \\
\hline Therapeutic ambulation & $6(3.2)$ & $2(33.3)$ & $4(66.7)$ & \\
\hline Nonambulatory & $144(60.6)$ & $41(36.0)$ & $73(64.0)$ & \\
\hline Ventricular shunt & & & & $<0.001$ \\
\hline No & $52(27.7)$ & $34(65.4)$ & $18(34.6)$ & \\
\hline Yes & $136(72.3)$ & $48(35.3)$ & $88(64.7)$ & \\
\hline No. of ventricular shunt revisions & & & & 0.010 \\
\hline 0 & $98(52.1)$ & $53(54.1)$ & $45(45.9)$ & \\
\hline $1-3$ & $64(34.0)$ & $21(32.8)$ & $43(67.2)$ & \\
\hline$>3$ & $26(13.8)$ & $8(30.8)$ & $18(69.2)$ & \\
\hline
\end{tabular}

Values are presented as the number of patients (\%) unless stated otherwise. Boldface type indicates statistical significance.

* Includes part- and full-time employment, as well as those seeking work, occasional worker, volunteer, child, student, retired, or homemaker.

$\dagger$ Student's t-test and logistic regression were used for comparison of means; the chi-square test was used for comparison of proportions.

$\ddagger$ BMI data available for 156 patients.

$\S$ Insurance status available for 180 patients.

technical school, 50 (26.6\%) had completed some college, $20(10.6 \%)$ had a college degree, and 7 (3.7\%) held an advanced degree. One hundred six patients $(56.4 \%)$ reported that they identified themselves as permanently disabled. Of the remaining 82 patients, $33(17.6 \%)$ were employed either full or part time; $26(13.8 \%)$ were active students; and $23(12.2 \%)$ were volunteers, currently seeking work, occasional workers, retired, or working as a homemaker. Eighty-three patients (46.1\%) used commercial insurance, 60 patients (33.3\%) were on Medicaid, 31 patients (17.2\%) were on Medicare, and 6 patients (3.3\%) reported "other" for their insurance coverage. Insurance status was missing for 8 patients. Forty-five patients (23.9\%) reported having an active bowel management program, while $133(70.7 \%)$ had an active bladder management program. One hundred forty-four patients $(60.6 \%)$ were nonambulatory, $6(3.2 \%)$ ambulated with assistance, $14(7.4 \%)$ were ambulatory in the home, and 54 (28.7\%) were independently ambulatory in the community. One hundred thirty-six patients (72.3\%) had a ventricular shunt, and 90 patients underwent at least 1 ventricular shunt revision. Frequency of stool incontinence, urinary incontinence, and functional lesion level is presented in Fig. 1.

On bivariate analysis (Table 1), permanent disability was significantly associated with primary diagnosis $(\mathrm{p}<$ $0.001)$, education level $(\mathrm{p}<0.001)$, insurance status $(\mathrm{p}<$ $0.001)$, frequency of stool incontinence $(\mathrm{p}<0.001)$, frequency of urinary incontinence $(\mathrm{p}=0.037)$, ambulation status $(p=0.021)$, and presence of a ventricular shunt ( $p$ $<0.001$ ). The number of ventricular shunt revisions was significantly associated with permanent disability $(0$ and $1-3$ vs $>3$ shunt revisions, $p=0.010$ ).

\section{Multivariate Analysis}

On multivariate analysis (Table 2), education, diagnosis, and stool incontinence were independently associated with self-identification as permanently disabled. Relative to completion of primary and/or secondary school, completion of technical school (OR $0.01,95 \%$ CI $0-0.40 ; \mathrm{p}$ $=0.021)$, some college $(\mathrm{OR} 0.22,95 \%$ CI $0.08-0.53 ; \mathrm{p}<$ 0.001 ), college degree (OR 0.06, 95\% CI 0.003-0.66; $p=$ 0.019 ), and holding an advanced degree (OR $0.12,95 \%$ CI $0.03-0.45 ; \mathrm{p}=0.002$ ) were associated with a lower likelihood of permanent disability. Due to the small number of patients with diastematomyelia and "other" spinal dysraphism, we collapsed the primary diagnosis variable into 2 categories for the multivariate analysis: 1) open myelomeningocele and 2) closed spinal dysraphism. Relative to open myelomeningocele, closed spinal dysraphism was associated with permanent disability status (OR $0.20,95 \%$ CI $0.04-0.90 ; \mathrm{p}=0.036$ ).

Additionally, stool incontinence occurring at least daily (OR 6.41, 95\% CI 1.56-32.90; $\mathrm{p}=0.009$ ) or more than weekly (OR 3.43, 95\% CI 1.10-11.89; $\mathrm{p}=0.033$ ) was positively associated with increased odds of permanent disability. There was a suggestion of a dose-response relationship with respect to the influence of education achieved and frequency of stool incontinence on likelihood of permanent disability (Fig. 2). Urinary incontinence, race, ambulation status, presence of a ventricular shunt, and number of ventricular shunt revisions did not correlate with permanent disability on multivariate analysis.

An ROC curve was additionally fit for permanent disability as a function of those variables that remained sig- 


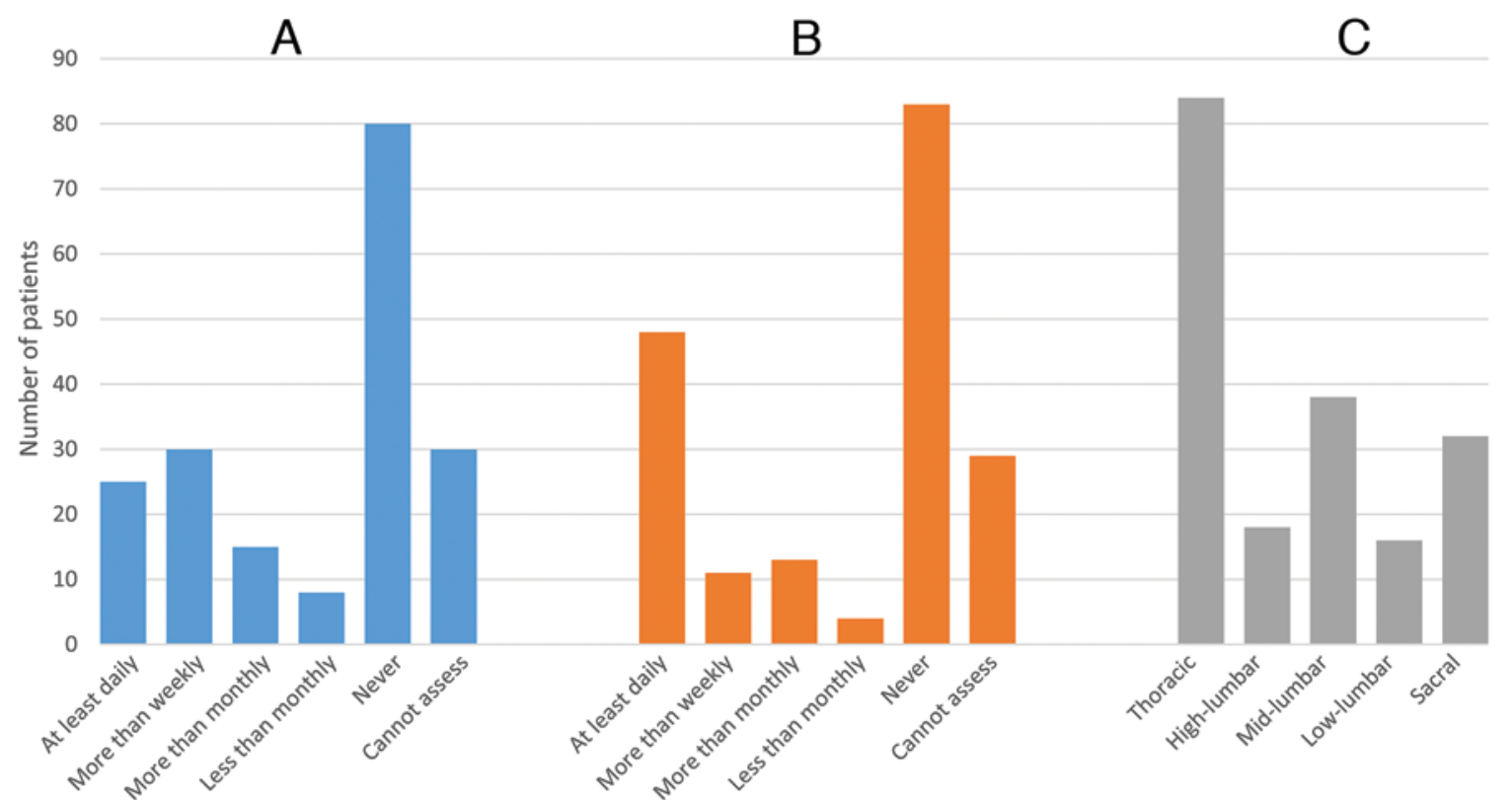

FIG. 1. Bar graph showing the frequency of stool incontinence (A), urinary incontinence (B), and functional lesion level (C) of cohort. Figure is available in color online only.

nificantly associated with permanent disability on multivariate analysis, with an area under the curve of 0.82 (Fig. 3).

\section{Discussion}

In this study of 188 adults with spina bifida, we found education level, stool incontinence, and diagnosis (open vs closed spinal dysraphism) to be independent predictors of self-reported permanent disability, which can be viewed as a surrogate for functional community participation. These findings provide a more granular description of the relationship between the various factors influencing community engagement in adults with spina bifida. We additionally observed a subjective dose-response effect on permanent disability by both frequency of stool incontinence and level of education.

\section{Stool Continence and Employment}

Stool incontinence had a marked impact on permanent disability in our multivariate model, with patients experiencing daily incontinence carrying an over 6-fold likelihood of permanent disability relative to patients with less than monthly or no incontinence. Bowel dysfunction carries both physical and psychological consequences, impairing psychosocial development and self-esteem ${ }^{32}$ and greatly impacting quality of life..$^{7,16,28}$ In one study, $66 \%$ of adults with spina bifida reported stool incontinence to be a significant barrier to attending school, maintaining relationships, and obtaining employment. ${ }^{14}$

Conservative bowel management programs include dietary changes, stool softeners and bulking agents, suppositories, retrograde colonic enemas, and digital evacuation..$^{11}$ Continence rates with these methods range from $67 \%$ to $80 \%$ and positively impact quality of life. ${ }^{39}$ Anterograde colonic enema through a surgical ostomy may also be recommended for select individuals, with resultant continence rates exceeding $80 \%$ and a reduced need for medication or rectal maneuvers. ${ }^{15}$ Despite the availability of effective regimens, only $24 \%$ of our population reported having an active bowel regimen program. Reluctance to address bowel incontinence due to stigma or lack of awareness of treatment options is common in adults with spina bifida. ${ }^{20}$ Our findings underscore the importance of addressing bowel continence, with a significant potential impact on social functioning and employment.

In a Danish population, Van Mechelen et al. found stool or urine incontinence to be predictive of employment status on bivariate but not multivariate analysis. ${ }^{38}$ Separating stool and urine incontinence and distinguishing frequency of incontinence may explain the difference observed in our population. Consistent with prior studies, our study showed stool incontinence to be a significant predictor in the multivariate model, while urinary incontinence did not have a meaningful effect on reported permanent disability in this population. ${ }^{4,38}$

\section{Education and Employment}

Multiple studies have been reported on predictors of employment status in cerebral palsy, but data on adults with spina bifida in the US are limited and frequently conflicting. Furthermore, comparisons between the present study and existing literature are difficult due to differences in the way employment status is measured and defined. IQ scores have been positively correlated with employment rates in these individuals, ${ }^{1,29}$ while level of education may also be a proxy for intelligence, motivation, perseverance, or other positively adaptive behaviors. Among adults with cerebral palsy without cognitive impairment in the Netherlands, college education is associated with higher rates of employment. ${ }^{23}$ In both Sweden and the Netherlands, a 
TABLE 2. Logistic regression models of permanent disability by covariates significantly associated on bivariate analysis

\begin{tabular}{|c|c|c|c|}
\hline Variable & OR & $95 \% \mathrm{Cl}$ & $\mathrm{p}$ Value $\dagger$ \\
\hline Education & & & $<0.001$ \\
\hline Primary/secondary & Ref & Ref & \\
\hline Technical school & 0.01 & $0-0.40$ & 0.021 \\
\hline Some college & 0.22 & $0.08-0.53$ & $<0.001$ \\
\hline College degree & 0.06 & $0.003-0.66$ & 0.019 \\
\hline Advanced degree & 0.12 & $0.03-0.45$ & 0.002 \\
\hline Primary diagnosis & & & 0.036 \\
\hline Open myelomeningocele & Ref & Ref & \\
\hline Closed spinal dysraphism & 0.20 & $0.04-0.90$ & 0.036 \\
\hline Stool incontinence & & & 0.065 \\
\hline Never & Ref & Ref & \\
\hline At least daily & 6.41 & $1.56-32.90$ & 0.009 \\
\hline Less than daily, more than weekly & 3.43 & $1.10-11.89$ & 0.033 \\
\hline $\begin{array}{l}\text { Less than weekly, more than } \\
\text { monthly }\end{array}$ & 3.31 & $0.77-16.12$ & 0.109 \\
\hline Less than monthly & 0.97 & $0.16-6.77$ & 0.974 \\
\hline Cannot assess & 1.01 & $0.19-5.42$ & 0.992 \\
\hline Urinary incontinence & & & 0.151 \\
\hline Never & Ref & Ref & \\
\hline At least daily & 0.94 & $0.32-2.70$ & 0.914 \\
\hline Less than daily, more than weekly & 2.21 & $0.36-16.55$ & 0.396 \\
\hline $\begin{array}{l}\text { Less than weekly, more than } \\
\text { monthly }\end{array}$ & 1.55 & $0.38-6.84$ & 0.543 \\
\hline Less than monthly & $\infty$ & $4.35-\infty$ & 0.0059 \\
\hline Cannot assess & 0.97 & $0.19-4.78$ & 0.970 \\
\hline Race & & & 0.235 \\
\hline White & Ref & Ref & \\
\hline Black & 2.68 & $0.86-9.04$ & 0.089 \\
\hline Other & 0.94 & $0.02-93.9$ & 0.975 \\
\hline Independent ambulation & & & 0.745 \\
\hline Community ambulation & Ref & Ref & \\
\hline Household ambulation & 1.89 & $0.38-10.13$ & 0.440 \\
\hline Therapeutic ambulation & 1.73 & $0.21-17.69$ & 0.616 \\
\hline Nonambulatory & 1.71 & $0.64-4.64$ & 0.285 \\
\hline Ventricular shunt & & & 0.484 \\
\hline No & Ref & Ref & \\
\hline Yes & 1.55 & $0.46-5.47$ & 0.484 \\
\hline No. of ventricular shunt revisions & & & 0.891 \\
\hline 0 & Ref & Ref & \\
\hline $1-3$ & 0.97 & $0.36-2.54$ & 0.948 \\
\hline$>3$ & 1.27 & $0.39-4.33$ & 0.695 \\
\hline
\end{tabular}

Ref $=$ reference .

higher level of education did increase work participation in adults with spina bifida. ${ }^{37,38}$ The generalizability of these findings to a US-based population is uncertain, however, as significant wage subsidies facilitate employment for individuals with disabilities in both countries. ${ }^{36}$ While college education does appear to improve employment rates in the US for people with a range of disabilities in their 20s and 30s, significant employment loss occurs in the later decades. ${ }^{24}$ While age was not associated with perceived disability in the present study, only 8 individuals at least 50 years of age were included. Aging with congenital disabilities is relatively unexplored, and whether a similar relationship holds true for individuals with spina bifida remains unclear.

We have observed that patients who achieve a higher level of education are less likely to consider themselves permanently disabled. Furthermore, increasing levels of education correlate with a lower likelihood of perceived disability. Technical school remains an outlier, with technical school completion associated with the lowest risk of permanent disability status. However, the observed effect may have been skewed by the very small number of patients completing technical school in our population. Nevertheless, attending a vocational school may represent an attainable goal for many individuals, adding purpose and improving quality of life in this population.

\section{Medical Factors Influencing Community Participation}

In one study, $85 \%$ of patients with spina bifida were attending or had graduated from high school and/or college, and a similar percentage had social bladder continence. ${ }^{6}$ However, community participation in these individuals is historically low, with only $30 \%$ involved in weekly organized community activities. ${ }^{5}$ It is generally accepted that multidisciplinary teams provide superior care for this population. ${ }^{13}$ Overall physical health has been shown to correlate with employment status, ${ }^{8}$ and previous reports have found ventricular shunt revision to be a negative predictor of long-term achievement. ${ }^{12}$ While ventricular shunting and number of ventricular shunt revisions were associated with permanent disability in our univariate analysis, they were not significant predictors on multivariate analysis. While ventricular shunt infections have been negatively correlated with cognitive function, ventricular shunt revisions in the absence of infection have not been associated with declines in IQ scores.9,27

Our results differ from those of prior studies because we included continence and level of education, functional metrics that we find to be the best predictors of permanent disability. Furthermore, while previous work has shown a link between the level of neurological function and survival and need for care in adulthood, we found no correlation between functional level or ambulatory status and employment/disability. ${ }^{25,26}$ Seemingly minor barriers such as transportation difficulties can also hinder work participation in patients with motor disabilities. ${ }^{19}$

Finally, even in the multivariate model, individuals with closed spinal dysraphism continued to report permanent disability far less frequently than those with open myelomeningocele. Since ambulation status, continence, and ventricular shunting were included in the multivariate model, we must consider other potential explanations such as cognitive function for the difference between these groups. Nevertheless, this finding is encouraging for the prospect of long-term success among patients with closed spinal dysraphism.

\section{School-to-Work and Pediatric-to-Adult Care Transitions}

For pediatric patients with chronic medical conditions, transitioning to adult care presents a formidable challenge. ${ }^{33,34}$ Patients and families are often reluctant to leave the familiar pediatric center and sometimes perceive a lack of interest among adult providers. Studies on transition to 


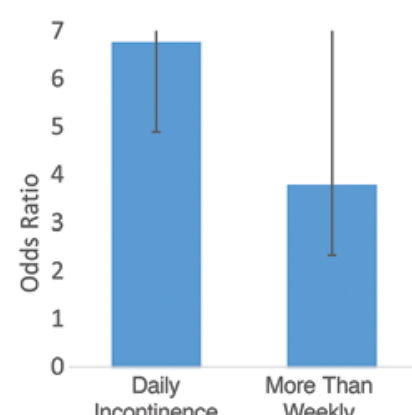

Incontinence Weekly
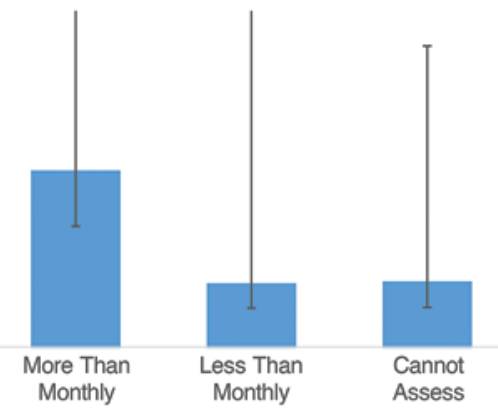
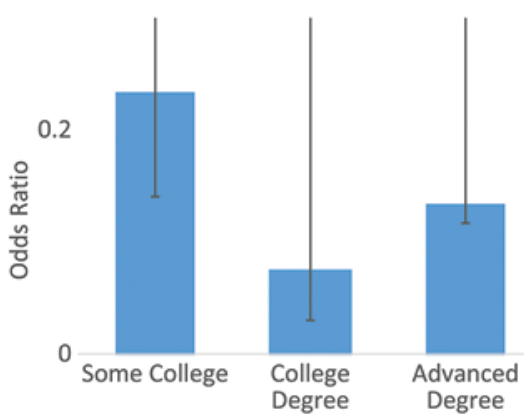

FIG. 2. Odds of permanent disability in multivariate logistic regression as a function of stool continence (left) and education status (right). Figure is available in color online only.

adult care have suggested that successful transitions are associated with adequate pretransition patient preparation, flexible timing of transition, early introduction to the adult clinic, and invested and coordinated adult providers. ${ }^{3,30}$ Similarly, school-to-work transitions require professional support, social support, consideration of transportation needs, and assistance coping with medical comorbidities, stigma, learning disabilities, and executive dysfunction. ${ }^{17,18}$

To build a successful transition program for children with spina bifida, engagement of the patient and family, as well as a range of medical and social teams, is essential. $^{22,35}$ The results from the present study suggest that highlighting the impact of stool continence and education in the pediatric clinic may be a high-yield transitional education topic and is worthy of further study.

\section{Limitations}

There are several limitations of our observational study design. Data were retrospectively reviewed, with potential for underreporting or inaccuracies in data reporting and coding. This study was nonrandomized, and our findings

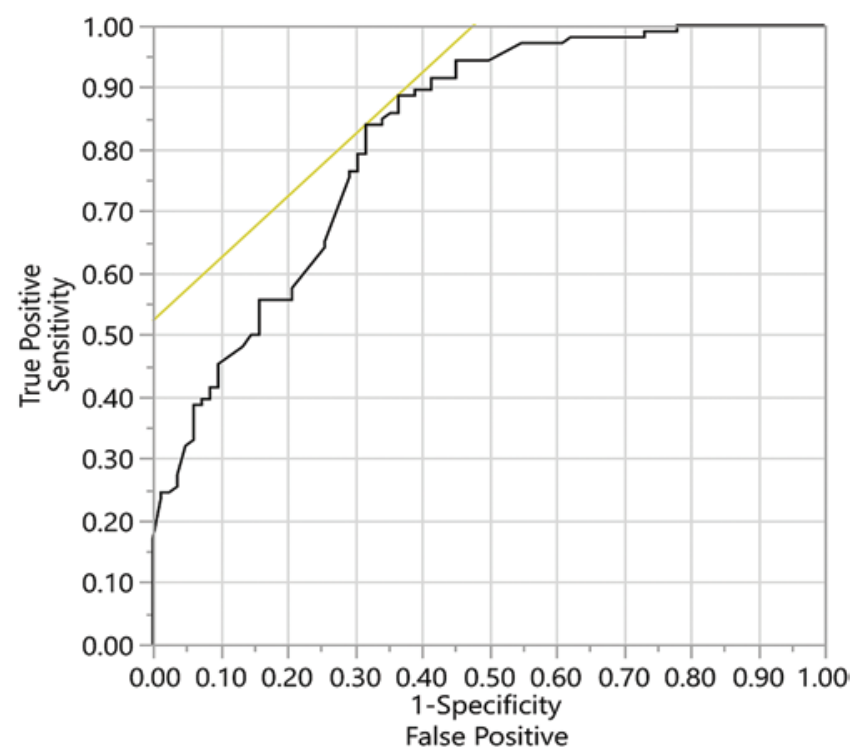

FIG. 3. ROC curve for permanent disability as a function of those variables significantly associated with permanent disability on multivariate analysis. Figure is available in color online only. may have been confounded by unmeasured factors for which we were unable to adjust. It is also unclear whether these findings are generalizable to adults with spine bifida who are treated at other institutions. In addition, we used patient self-reported permanent disability, rather than receipt of governmental disability benefits, due to the lack of sensitivity and specificity of that metric. Some patients may consider themselves permanently disabled but not receive disability benefits, while other patients may receive governmental disability benefits yet still engage in volunteer or part-time work. In a related issue, we elected not to include insurance status in our multivariate model, as insurance status is reflective of disability status, without necessarily representing a confounding variable. It is unsurprising that a high percentage of individuals identifying themselves as permanently disabled are on Medicaid, and equally unsurprising that a high percentage of people with commercial insurance do not identify themselves as permanently disabled. Given the constraints of our study design, we were unable to rigorously evaluate the independent effect of insurance status on permanent disability in this population. While community engagement influences health-related quality of life (HRQOL), it is important to note that we did not use validated HRQOL metrics in this study. Future work would be valuable to determine whether the same factors that influence permanent disability have a similar effect on HRQOL. Finally, it is possible that although the NSBPR uses a self-reported questionnaire, we had no means of capturing whether questions were answered by the patient or a surrogate. This could have differentially affected the responses from patients with poor cognitive function.

Despite these limitations, we think that our findings yield important insights. A strength of the current approach was the use of multivariate techniques to adjust for potential confounding variables. The interplay of medical, psychosocial, and socioeconomic factors in adults with spina bifida is highly complex, and the independent effect of each can be difficult to ascertain.

\section{Conclusions}

Adults with spina bifida face numerous barriers to fulfilling participation in society. Our findings suggest that both medical and psychosocial factors contribute to limiting these individuals in obtaining employment. Further studies are indicated to determine whether targeted medi- 
cal or social service interventions can have an outsized impact on employment status in this at-risk population. This study indicates that greater emphasis should be placed on bowel management in the pediatric years to establish a working bowel program prior to reaching adulthood. Furthermore, our study supports a need for counseling adults with spina bifida and their family members about the impact of advanced education in this population.

\section{Acknowledgments}

Dr. Davis completed this work as a Women's Leadership Council Clinical Scholar in the Department of Neurosurgery at the University of Alabama at Birmingham, supported by the Kaul Foundation. Dr. Rocque is supported by NIH Grant 1KL2TR001419, and by the Kaul Pediatric Research Institute of Children's of Alabama.

\section{References}

1. Barf HA, Post MWM, Verhoef M, Jennekens-Schinkel A, Gooskens RHJM, Prevo AJH: Restrictions in social participation of young adults with spina bifida. Disabil Rehabil 31:921-927, 2009

2. Bellin MH, Zabel TA, Dicianno BE, Levey E, Garver K, Linroth R, et al: Correlates of depressive and anxiety symptoms in young adults with spina bifida. J Pediatr Psychol 35:778-789, 2010

3. Binks JA, Barden WS, Burke TA, Young NL: What do we really know about the transition to adult-centered health care? A focus on cerebral palsy and spina bifida. Arch Phys Med Rehabil 88:1064-1073, 2007

4. Bomalaski MD, Teague JL, Brooks B: The long-term impact of urological management on the quality of life of children with spina bifida. J Urol 154:778-781, 1995

5. Boudos RM, Mukherjee S: Barriers to community participation: Teens and young adults with spina bifida. J Pediatr Rehabil Med 1:303-310, 2008

6. Bowman RM, McLone DG, Grant JA, Tomita T, Ito JA: Spina bifida outcome: a 25-year prospective. Pediatr Neurosurg 34:114-120, 2001

7. Choi EK, Im YJ, Han SW: Bowel management and quality of life in children with spina bifida in South Korea. Gastroenterol Nurs [epub ahead of print], 2015

8. Cox A, Breau L, Connor L, McNeely PD, Anderson PA, MacLellan DL: Transition of care to an adult spina bifida clinic: patient perspectives and medical outcomes. J Urol 186 (4 Suppl):1590-1594, 2011

9. Del Bigio MR: Neuropathological changes caused by hydrocephalus. Acta Neuropathol 85:573-585, 1993

10. Dicianno BE, Kurowski BG, Yang JMJ, Chancellor MB, Bejjani GK, Fairman AD, et al: Rehabilitation and medical management of the adult with spina bifida. Am J Phys Med Rehabil 87:1027-1050, 2008

11. Eire PF, Cives RV, Gago MC: Faecal incontinence in children with spina bifida: the best conservative treatment. Spinal Cord 36:774-776, 1998

12. Hunt GM, Oakeshott P, Kerry S: Link between the CSF shunt and achievement in adults with spina bifida. J Neurol Neurosurg Psychiatry 67:591-595, 1999

13. Kennedy A, Sloman F, Douglass JA, Sawyer SM: Young people with chronic illness: the approach to transition. Intern Med J 37:555-560, 2007

14. Krogh K, Lie HR, Bilenberg N, Laurberg S: Bowel function in Danish children with myelomeningocele. APMIS Suppl (109):81-85, 2003

15. Lemelle JL, Guillemin F, Aubert D, Guys JM, Lottmann H, Lortat-Jacob S, et al: A multicentre study of the management of disorders of defecation in patients with spina bifida. Neurogastroenterol Motil 18:123-128, 2006

16. Lemelle JL, Guillemin F, Aubert D, Guys JM, Lottmann H, Lortat-Jacob S, et al: Quality of life and continence in patients with spina bifida. Qual Life Res 15:1481-1492, 2006

17. Lindsay S, McPherson AC, Maxwell J: Perspectives of school-work transitions among youth with spina bifida, their parents and health care providers. Disabil Rehabil 39:641652,2017

18. Liptak GS, Garver K, Dosa NP: Spina bifida grown up. J Dev Behav Pediatr 34:206-215, 2013

19. Magill-Evans J, Galambos N, Darrah J, Nickerson C: Predictors of employment for young adults with developmental motor disabilities. Work 31:433-442, 2008

20. Mattsson S, Gladh G: Tap-water enema for children with myelomeningocele and neurogenic bowel dysfunction. Acta Paediatr 95:369-374, 2006

21. McDonnell GV, McCann JP: Issues of medical management in adults with spina bifida. Childs Nerv Syst 16:222-227, 2000

22. Mennito SH, Clark JK: Transition medicine: a review of current theory and practice. South Med J 103:339-342, 2010

23. Michelsen SI, Uldall P, Kejs AMT, Madsen M: Education and employment prospects in cerebral palsy. Dev Med Child Neurol 47:511-517, 2005

24. Mitchell JM, Adkins RH, Kemp BJ: The effects of aging on employment of people with and without disabilities. Rehabil Couns Bull 49:157-165, 2006

25. Oakeshott P, Hunt GM, Poulton A, Reid F: Expectation of life and unexpected death in open spina bifida: a 40-year complete, non-selective, longitudinal cohort study. Dev Med Child Neurol 52:749-753, 2010

26. Oakeshott P, Hunt GM, Poulton A, Reid F: Open spina bifida: birth findings predict long-term outcome. Arch Dis Child 97:474-476, 2012

27. Ralph K, Moylan P, Canady A, Simmons S: The effects of multiple shunt revisions on neuropsychological functioning and memory. Neurol Res 22:131-136, 2000

28. Rendeli C, Ausili E, Tabacco F, Caliandro P, Aprile I, Tonali $\mathrm{P}$, et al: Assessment of health status in children with spina bifida. Spinal Cord 43:230-235, 2005

29. Roach JW, Short BF, Saltzman HM: Adult consequences of spina bifida: a cohort study. Clin Orthop Relat Res 469:1246-1252, 2011

30. Rutishauser C, Akré C, Surìs JC: Transition from pediatric to adult health care: expectations of adolescents with chronic disorders and their parents. Eur J Pediatr 170:865-871, 2011

31. Sawin KJ, Bellin MH: Quality of life in individuals with spina bifida: a research update. Dev Disabil Res Rev 16:47-59, 2010

32. Sawin KJ, Thompson NM: The experience of finding an effective bowel management program for children with spina bifida: the parent's perspective. J Pediatr Nurs 24:280-291, 2009

33. Scal P, Evans T, Blozis S, Okinow N, Blum R: Trends in transition from pediatric to adult health care services for young adults with chronic conditions. J Adolesc Health 24:259264, 1999

34. Steinbeck KS, Brodie L, Towns SJ: Transition in chronic illness: who is going where? J Paediatr Child Health 44:478482, 2008

35. Stellman-Ward G, Bannister CM, Lewis M: Assessing the needs of the adult with spina bifida. Eur J Pediatr Surg 3 (Suppl 1):14-16, 1993

36. Törnbom M, Jonsson U, Sunnerhagen KS: Work participation among middle-aged persons with cerebral palsy or spina bifida - a longitudinal study. Disabil Health J 7:251-255, 2014 
37. Valtonen K, Karlsson AK, Alaranta H, Viikari-Juntura E: Work participation among persons with traumatic spinal cord injury and meningomyelocele1. J Rehabil Med 38:192-200, 2006

38. van Mechelen MC, Verhoef M, van Asbeck FWA, Post MWM: Work participation among young adults with spina bifida in the Netherlands. Dev Med Child Neurol 50:772777, 2008

39. Velde SV, Biervliet SV, Bruyne RD, Winckel MV: A systematic review on bowel management and the success rate of the various treatment modalities in spina bifida patients. Spinal Cord 51:873-881, 2013

\section{Disclosures}

The authors report no conflict of interest concerning the materi- als or methods used in this study or the findings specified in this paper.

\section{Author Contributions}

Conception and design: Rocque, Hopson, Blount, Carroll, Wilson, Powell, McLain. Acquisition of data: Rocque, Hopson, Carroll, Wilson, Powell. Analysis and interpretation of data: Rocque, Davis. Drafting the article: Rocque, Davis. Critically revising the article: Rocque, Davis, Hopson, Blount, Carroll, Powell, McLain. Reviewed submitted version of manuscript: all authors. Statistical analysis: Rocque, Davis. Administrative/technical/material support: Rocque, Carroll, Wilson. Study supervision: Rocque, Wilson, McLain.

\section{Correspondence}

Brandon G. Rocque, Department of Neurosurgery, University of Alabama at Birmingham, 600 7th Ave. South, Birmingham, AL 35233. email: brandon.rocque@childrensal.org. 